\title{
Target Sign of Third Ventricle in Basilar Dolichoectasia with Multiple Clinical Presentations: A Case Report
}

\author{
Akshay S. Patil ${ }^{1}$ Sandeep Iratwar ${ }^{1}$ Chetan Rathod
${ }^{1}$ Department of Neurosurgery, Jawaharlal Nehru Medical College and Acharya Vinoba Bhave Rural Hospital, Sawangi, Wardha, Maharashtra, India

\author{
Paresh Korde ${ }^{1}$
}

\author{
Address for correspondence Akshay S. Patil, MS, MCh, \\ Department of Neurosurgery, Jawaharlal Nehru Medical College \\ and Acharya Vinoba Bhave Rural Hospital, Sawangi, Wardha, \\ Maharashtra 442001, India (e-mail: dr.akshayarbat@hotmail.com).
}

\begin{abstract}
Keywords

- basilar dolichoectasia

- hydrocephalus

- subarachnoid hemorrhage

Basilar dolichoectasia (BDE) is an uncommon anatomical variant usually detected incidentally or during stroke evaluation. BDE can occasionally become symptomatic and may present with stroke (infarct or hemorrhage), raised intracranial pressure due to obstructive hydrocephalus, or with cranial nerve palsies. We present a unique case of BDE presenting with obstructive hydrocephalus, stroke, and cranial nerve palsy in single patient and propose a radiological sign (target sign of third ventricle), which could aid in imaging diagnosis and further management.
\end{abstract}

\section{Introduction}

Basilar dolichoectasia (BDE) is a rare anatomical variant of basilar artery with variable clinical presentation. It is usually detected incidentally and is essentially a radiological diagnosis. BDE may rarely present as posterior circulation ischemic stroke, intracerebral bleed subarachnoid hemorrhage (SAH), cranial nerve palsies, and rarely with obstructive hydrocephalus due to compression on midbrain, aqueduct, and floor of third ventricle or the foramen of Monro. ${ }^{1}$ We are documenting a unique case of a 38-year-old male presenting with raised intracranial pressure (ICP) in the form of obstructive hydrocephalus and right facial lower motor neuron palsy. The imaging characteristics and diagnostic clues are also discussed.

\section{Case History}

A38-year-old male, laborer by occupation, presented with complaints of raised intracranial since 5 days. Neurological examination revealed papilloedema with right lower motor neuron type facial (VII nerve) palsy (H B grade III) and gait ataxia. Computerized Tomogram (CT) of the brain plain ( - Fig. 1) revealed biventricular hydrocephalus with hyperdense lesion in the basal cistern and floor of third ventricle. Magnetic resonance imaging (MRI and MR angiogram; - Fig. 2) revealed a dolichoectatic high-riding basilar artery (BA) compressing the

DOI https://doi.org/

$10.1055 / \mathrm{s}-0039-3402536$

ISSN 2277-954X. mid-third of the floor of third ventricle with resultant biventricular hydrocephalus. T1- and T2-weighted and fluid-attenuated inversion recovery (FLAIR) axial images of dolichoectatic BA showed target sign (BA along the floor of third ventricle with elevating the floor; - Fig. 1). MRI brain also showed blooming on susceptibility-weighted images (SWIs) sequence along bilateral basal ganglia suggestive of micro bleed. The patient further underwent digital subtraction angiogram (DSA - Fig. 2), which revealed an elongated high-riding BA $2.5 \mathrm{~cm}$ above posterior clinoid (Smoker's grade 3) and BA diameter of $6.4 \mathrm{~mm}$ was noted. Patient underwent right ventriculoperitoneal (VP) shunt in view of biventricular hydrocephalus following which his headache improved. He was initiated on antiplatelet prophylaxis to prevent further ischemic events.

\section{Discussion}

BDE refers to an anatomical variant characterized by dilatation and elongation of the BA. Knowledge regarding the natural history and progression of this rare entity is limited and progressive stoke is common cause of morbidity and mortality depending upon severity of condition at diagnosis. ${ }^{1,2}$ The incidence ranges from 0.06 to $5.8 \%$ with a prevalence of 3.1 to $4.4 \%{ }^{1,3,4}$ Males are more commonly affected and they become symptomatic mostly in the sixth to eighth decade. 

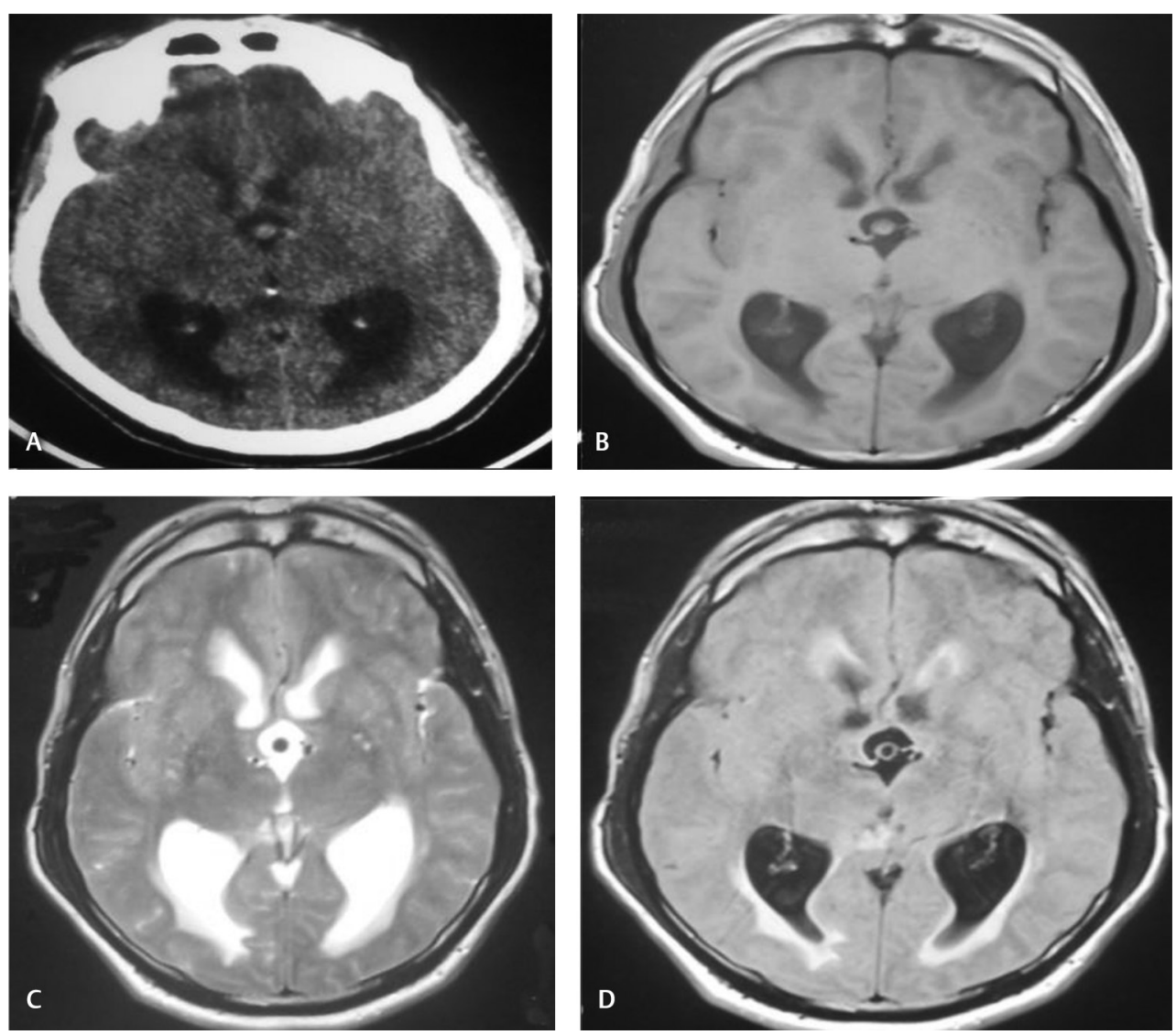

Fig. 1 (A) CT brain axial images reveal hyperdense basilar artery in the floor of third ventricle appears as bull's eye or target sign. (B-D) Axial T1-weighted MR images reveal iso- to hyperintense signal in this lesion with signal void on T2 and FLAIR images. On T2-weighted MR images, this appearance may mimic a "target sign" with central flow void surrounded by hyperintense CSF signal. CSF, cerebrospinal fluid; CT, computed tomography; FLAIR, fluid-attenuated inversion recovery; MR, magnetic resonance.

The clinical manifestation can vary from a benign asymptomatic course to an extremely debilitating condition. When symptomatic, an ischemic pontine infarct is the most common presentation of BDE (20-30\%). Other modes of presentation include intracerebral hemorrhage, cranial nerve palsies, obstructive hydrocephalus, subarachnoid hemorrhage, trigeminal neuralgia, and hemifacial spasm. ${ }^{1,4}$ The etiopathogenesis of ischemic stroke in BDE is related to the stretching and distortion of branches of BA leading to stasis and reduction in forward flow in a dilated artery and superimposed atherosclerosis resulting in thromboembolic phenomenon. ${ }^{5,6}$ In addition, some recent studies have shown an association between small vessel disease and BDE which could be another causative factor for lacunar infarcts. ${ }^{1}$ Cranial nerve palsies and neuralgia probably result from direct compression of tortuous and elongated vessel. ${ }^{7}$ The ectatic vessels are often associated with aneurismal dilatation which may present with SAH or bleed. ${ }^{6.8}$ Hydrocephalus is one of the rare presentation of BDE and may be communicating (postsubarachnoid hemorrhage) or noncommunicating obstructive hydrocephalus. ${ }^{9-14} \mathrm{BDE}$ can cause obstruction at cerebral aqueduct, midbrain, third ventricle, or as high as the foramen of Monro. Noncommunicating hydrocephalus or normal pressure hydrocephalus could be due to water hammer effect of BA on the foramen of Monro or third ventricle. $^{12}$
CT scan will reveal the hydrocephalus and a hyperdense lesion in the prepontine cistern which may be confused as a mass lesion as in our case. CT angiogram or DSA helps in visualizing the exact morphology and to rule out aneurysmal dilatations. MRI further delineates the anatomy and also helps to visualize the presence of small infarcts, and quantify the mechanical compression of cranial nerves if any. BA with flow void in the middle-third floor of third ventricle before bifurcation has typical appearance like a bull's eye. Target sign of third ventricle as we wish to name, it is a new finding which helps to exclude mass lesion or aneurysm in floor of third ventricle. It has not been described in literature so far.

BDE is defined as a BA diameter greater than $4.5 \mathrm{~mm}$ or deviation of any portion of the BA more than $10 \mathrm{~mm}$ from the shortest expected course or as a BA of more than $29.5 \mathrm{~mm}$ in length. ${ }^{7}$ Level of BA is variable and had been graded by Smoker et $\mathrm{a}^{15}$ into the following grades: grade 1 (bifurcation within the supra sellar cistern), grade 2 (bifurcation at the level of the third ventricle floor), and grade 3 (bifurcation indenting the third ventricle floor). Similarly, the BA lateral displacement too has been graded as follows: grade 1 (BA located in the medial to lateral margin of the clivus or the dorsum sella), grade 2 (BA located lateral to those landmarks), and grade 3 (BA located in the cerebellopontine angle). Our patient had grade-III bifurcation which is very rare and grade-I displacement. Our patient had obstruction 

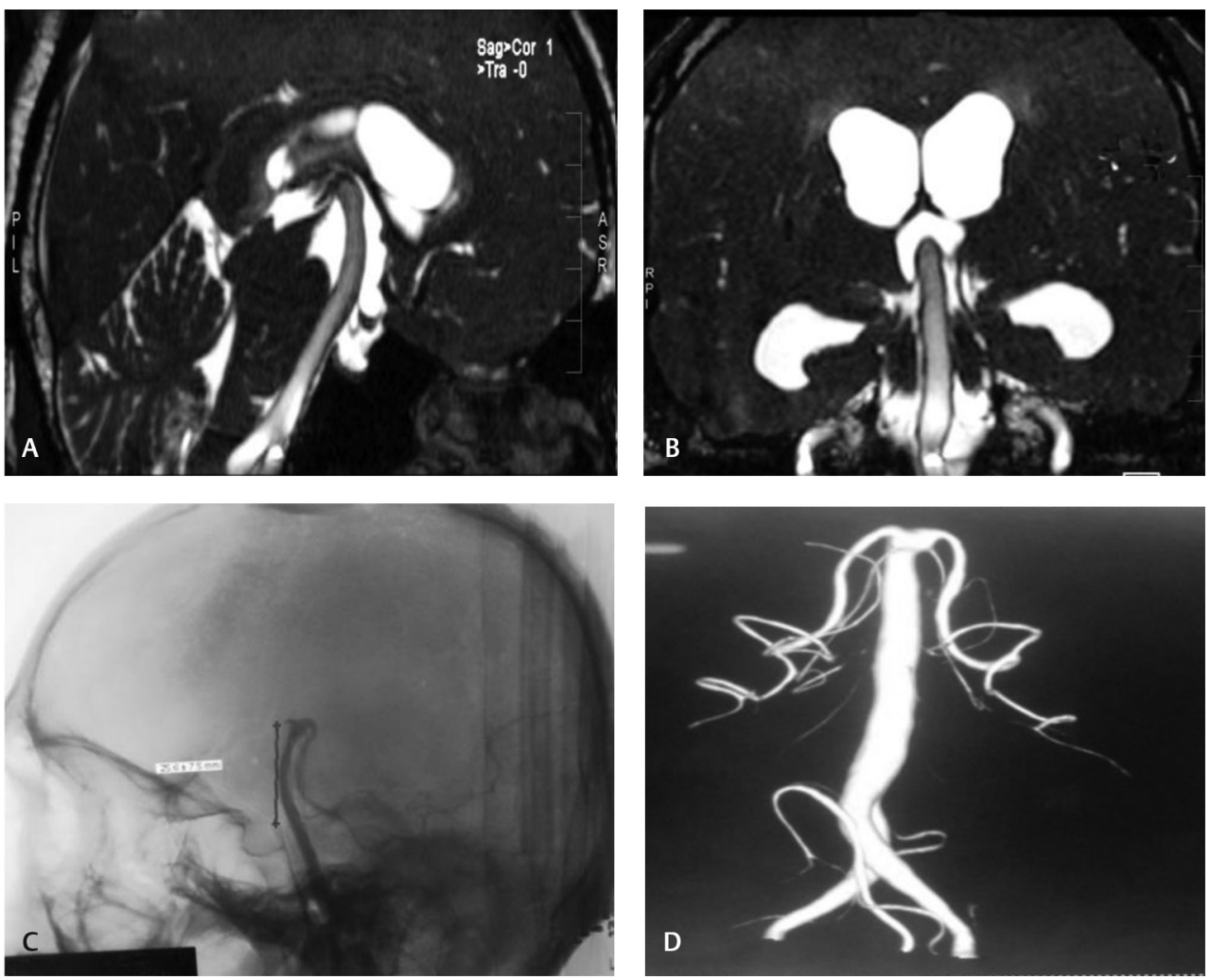

Fig. 2 (A, B) MRI sagittal and coronal images showing dolicoectatic basilar artery elevating and compressing the floor of the third ventricle. (C, D) DSA confirms the presence of a dolichoectatic basilar artery reaching $25 \mathrm{~mm}$ above the level of posterior clinoid. Maximum diameter was $6.5 \mathrm{~mm}$. No aneurysms were seen. However, there was stagnation of flow through the basilar artery. DSA, digital substraction angiogram; MRI, magnetic resonance imaging.

Table 1 Case reports of symptomatic hydrocephalus due to BDE refused surgery

\begin{tabular}{|c|c|c|c|c|}
\hline No. & Name & Year of publication & Age $(y) /$ sex & Management \\
\hline 1 & Breig et $\mathrm{al}^{16}$ & 1967 & 3 cases, no description & No details \\
\hline 2 & Ekbom et al ${ }^{11}$ & 1969 & 6 cases, no data & No details \\
\hline 3 & Rozario et al ${ }^{17}$ & 1978 & $57 / \mathrm{M}$ & Unilateral VP shunt \\
\hline 4 & Healy et al ${ }^{18}$ & 1988 & $50 / \mathrm{M}$ & Unilateral VP shunt \\
\hline 5 & Braneo et al ${ }^{19}$ & 1993 & $58 / \mathrm{M}$ & No details \\
\hline 6 & Aiba T et al ${ }^{9}$ & 1995 & $72 / F$ & Unilateral VP shunt \\
\hline 7 & Ricci et al $^{13}$ & 2000 & $55 / \mathrm{M}$ & Bilateral VP shunt \\
\hline 8 & Weber et $\mathrm{al}^{20}$ & 2002 & $69 / \mathrm{M}$ & Bilateral VP shunt \\
\hline 9 & Thiex et $\mathrm{al}^{21}$ & 2006 & $54 / \mathrm{M}$ & Unilateral VP shunt \\
\hline 10 & Siddiqui et al ${ }^{14}$ & 2008 & $71 / F$ & Unilateral VP shunt \\
\hline 11 & Kausal et al ${ }^{22}$ & 2011 & $60 / \mathrm{M}$ & Unilateral VP shunt \\
\hline 12 & Seshadri et al ${ }^{23}$ & 2012 & $45 / \mathrm{M}$ & Unilateral VP shunt \\
\hline 13 & Celik et a ${ }^{24}$ & 2013 & $47 / \mathrm{M}$ & Unilateral VP shunt + endoscopic exploration \\
\hline 14 & Zisimopoulou et al ${ }^{25}$ & 2015 & $48 / \mathrm{M}$ & Refused Sx \\
\hline 15 & Ebrahinzadeh et a ${ }^{26}$ & 2016 & $68 / \mathrm{M}$ & Endoscopic septostomy and Unilateral VP shunt \\
\hline 16 & Present case & 2018 & $38 / \mathrm{M}$ & Unilateral VP shunt \\
\hline
\end{tabular}

Abbreviations: F, female; M, male; VP, ventriculoperitoneal.

to cerebrospinal fluid (CSF) flow at midpart of the third ventricle, which is an extremely rare site for obstruction and ours study is probably the second such case reported in literature. A definite etiology for the lower motor neuron (LMN) facial palsy could not be explained, and we presume it to be caused by microemboli with minor brain stem stroke or due to the direct compression of the ectatic vessel or stretching on the nuclear or cisternal portion of the seventh cranial nerve. 
Till date, only 15 cases ( $\mathbf{- T a b l e} \mathbf{1}$ ) have been reported with symptomatic hydrocephalus as presentation of BDE. Our case is unique showing multiple presentations (hydrocephalus, microbleed/facial nerve palsy) in single patient with BDE. Symptomatic patients with hydrocephalus need emergency CSF diversion procedure either VP shunt or endoscopic septostomy with shunt according to the level of obstruction. Till date, no other permanent procedure for hydrocephalus due to BDE has been published endoscopic third ventriculostomy can be dangerous in situation like ours where the BA bifurcation is at the mid-third of the floor of the third ventricle and close to the foramen of Monro. Endovascular procedures still not established as treatment due to longer curvature and course. Role of antiplatelets and antiaggregants are in use but still debatable. Microvascular decompression can be helpful in neuralgia and cranial nerve palsy but need further endorsement with more studies. Randomized trials comparing efficacy of different treatment are lacking and needed urgently.

\section{Conclusion}

BDE is a rare anatomical condition which can be having various presentations of which obstructive hydrocephalus necessitate immediate surgical intervention. Target sign of the third ventricle is a useful radiological sign, which helps us to give diagnosis of BDE. VP shunt is preferred over endoscopic third ventriculostomy to avoid injuring the ectatic and tortuous BA. Endoscopic septostomy, followed by VP shunt, is also another surgical option. Definitive treatment for hydrocephalus has not established but needed further randomized trials.

\section{Funding}

None.

\section{Conflict of Interest}

None declared.

\section{References}

1 Passero SG, Rossi S, Giannini F. Natural history of vertebrobasilar dolichoectasia. Neurology 2008;70(1):66-72

2 Mangrum WI, Huston J III, Link MJ, et al. Enlarging vertebrobasilar nonsaccular intracranial aneurysms: frequency, predictors, and clinical outcome of growth. J Neurosurg 2005;102(1):72-79

3 Nakamura Y, Hirayama T, Ikeda K. Clinicoradiologic features of vertebrobasilar dolichoectasia in stroke patients. J Stroke Cerebrovasc Dis 2012;21(1):5-10

4 Yu YL, Moseley IF, Pullicino P, McDonald WI. The clinical picture of ectasia of the intracerebral arteries. J Neurol Neurosurg Psychiatry 1982;45(1):29-36
5 Kumral E, Kisabay A, Ataç C, Kaya C, Calli C. The mechanism of ischemic stroke in patients with dolichoectatic basilar artery. Eur J Neurol 2005;12(6):437-444

6 Steel JG, Thomas HA, Strollo PJ. Fusiform basilar aneurysm as a cause of embolic stroke. Stroke 1982;13(5):712-716

7 Ubogu EE, Zaidat OO. Vertebrobasilar dolichoectasia diagnosed by magnetic resonance angiography and risk of stroke and death: a cohort study. J Neurol Neurosurg Psychiatry 2004; 75(1):22-26

8 Echiverri HC, Rubino FA, Gupta SR, Gujrati M. Fusiform aneurysm of the vertebrobasilar arterial system. Stroke 1989; 20(12):1741-1747

9 Aiba T, Nakazawa T. Non-communicating hydrocephalus due to megadolichobasilar artery-case report. Neurol Med Chir (Tokyo) 1995;35(2):104-106

10 Branco G, Goulão A, Ferro JM. MRI in aqueduct compression and obstructive hydrocephalus due to an ecstatic basilar artery. Neuroradiology 1993;35(6):447-448

11 Ekbom K, Greitz T, Kugelberg E. Hydrocephalus due to ectasia of the basilar artery. J Neurol Sci 1969;8(3):465-477

12 Marinescu M, Remy A, Dufour H, Derome P, Cambon H. [A peculiar mechanism of hydrocephalus: the "water-hammering" effect]. Neurochirurgie 1998;44(2):117-120

13 Ricci G, Lenzi J, Esposito V. Hydrocephalus caused by dolichoectatic basilar artery. Case report. J Neurosurg Sci 2000; 44(3):155-158

14 Siddiqui A, Chew NS, Miszkiel K. Vertebrobasilar dolichoectasia: a rare cause of obstructive hydrocephalus: case report. $\mathrm{Br}$ J Radiol 2008;81(964):e123-e126

15 Smoker WRK, Corbett JJ, Gentry LR, Keyes WD, Price MJ, McKusker S. High-resolution computed tomography of the basilar artery: 2. Vertebrobasilar dolichoectasia: clinicalpathologic correlation and review. Am J Neuroradiol 1986;7(1): $61-72$

16 Breig A, Ekbom K, Greitz T, Kugelberg E. Hydrocephalus due to elongated basilar artery. A new clinicoradiological syndrome. Lancet 1967; 1:874-875

17 Rozario RA, Levine HL, Scott RM. Obstructive hydrocephalus secondary to an ectatic basilar artery surgical Neurology 1978;9(1):31-34

18 Healy JF, Well MV, HYPERLINK "https://www.ncbi.nlm.nih. gov/pubmed/?term=Rosenkrantz\%20H\%5BAuthor\%5D\&cauthor=true\&cauthor_uid=6976881" Rosenkrantz H. Computed tomography demonstration of enlarged ectatic basilar artery associated with obstruction of anterior third ventricle compression Radiology 1981;5(4):239-245

19 Branco G, Ginlao A, Ferro JM. MRI in aqueduct compression and obstructive HCP due to ectatic basilar artery. Neuroradiology 1993;35(6):447-448

20 Weber MA, Steiner T, Fiebach J. Ungewöhnliche Ursache einer akuten Bewusstseinseintrübung. Radiologe 2002;42: 833-836

21 Thiex R, Mull M. Basilar megadolicho trunk causing obstructive hydrocephalus at the foramina of Monro. Surgical Neurology 2006;65(2):199-201

22 Kansal R, Mahore A, Dange N, Kukreja S. Dolichoectasia of vertebrobasilar arteries as a cause of hydrocephalus. Journal of Neurosciences in Rural Practice 2011;2(1):62-64 
23 Seshadri R, Sadashiva N, Shukla D, Saini J, Pandey, P. Vertebrobasilar dolichoectasia presenting as symptomatic obstructive hydrocephalus: A case report with review of literature. IJNS 2012;1(2):165-168

24 Çelik Ö, Berkman ZM, Orakdöğen M, Ayan E, Somay H, Düzkalir HA. Obstructive hydrocephalus due to vertebrobasilar dolichoectasia: diagnostic and therapeutic considerations. J Neurol Surg A Cent Eur Neurosurg. 2013;74 Suppl 1: e4-e8
25 Zisimopoulou V, Ntouniadaki A, Aggelidakis P, Siatouni A, Gatzonis S, Tavernarakis A. Vertebrobasilar Dolichoectasia Induced Hydrocephalus: the Water-Hammer Effect. Clin Pract 2015;5(2):749

26 Ebrahimzadeh K, Bakhtevari MH, Shafizad M, Rezaei O. Hydrocephalus as a rare complication of vertebrobasilar dolichoectasia: a case report and review of literature. Surgical Neurology International 2017;8:256 